\title{
Cloning of embryos
}

\author{
R. S. Prather* and N. L. First \\ Department of Meat and Animal Science. College of Agricultural and Life Sciences, \\ University of Wisconsin, Madison, Wisconsin 53706, USA
}

\begin{abstract}
Summary. Nuclear transfer for the study of differentiation in amphibians has been used since the 1950 s, but not until recently have the same procedures been applied successfully to some mammals. Nuclear transfer, as developed for the amphibian, is successful in sheep, cattle, rabbit, and pig, but not mouse embryos. This fact is discussed in relation to the species-specific timing of the activation of the zygotic genome. Nuclear transfer to an oocyte presumably results in a genomic reprogramming of the transferred nucleus. The limits of differentiation that can be reprogrammed have yet to be determined. Since the cells of early embryos are thought to have identical nuclear genomes, early embryos can be used as a source of donor nuclei; and, when combined with serial nuclear transfer, can theoretically produce an unlimited number of identical offspring. Cloning by splitting does not result in a reprogramming of the genome and is limited in the number of identical offspring that can result. Here we discuss some of the factors to consider concerning micromanipulation and nuclear reprogramming and how they relate to other embryo technologies.
\end{abstract}

Keywords: embryo; clone; nuclear transfer; micromanipulation; splitting

\section{Introduction}

The production of identical individuals may have many important applications in agriculture and science. Genomically identical individuals would be ideal controls for experiments as the only observable variations would be environmentally induced. The number of clones manufactured by splitting the embryo at a preimplantation stage is limited, whereas cloning by nuclear transfer can theoretically supply an unlimited number of individuals that have identical nuclear genomes. In cattle the increase in genetic gain attainable with cloning by splitting has been previously calculated (Nicholas \& Smith, 1983). The amount of genetic gain possible with a technique that can identify superior individuals (see 'Discussion') before creating large numbers can only result in even greater genetic progress, especially for traits of low heritability. At present, at least 3 cattle breeding companies are developing cloning by nuclear transfer for commercial uses. If the procedures become highly efficient and a large number of clones can be produced from a single embryo of potentially high production, cloning of embryos could be useful in the genetic improvement of pigs.

\section{Methods for cloning}

\section{Cloning by splitting}

In domestic animals, blastomeres from cleavage-stage embryos can be removed from the zona pellucida, transferred to surrogate zonae pellucidae and cultured (Willadsen, 1982). Compact morulae and early blastocyst-stage embryos can be mechanically split into two or more sections. This can be accomplished with micro-needles or razor blades, inside or outside of the zona

*Present address: Department of Animal Sciences, College of Agriculture, University of Missouri-Columbia, Columbia, MO 6521I, USA. 
pellucida (Willadsen, 1979; Ozil et al., 1982; Williams et al., 1982; Baker \& Shea, 1985). Details of the methods can be found in the respective papers.

\section{Cloning by nuclear transfer}

Two methods have been developed for the transfer of nuclei between early embryos. One is a surgical method, that requires that the plasma membranes of the cells be penetrated. In mammals this procedure is both more difficult to accomplish and less efficient in transferring nuclei than is a non-surgical procedure that incorporates cell fusion to facilitate the nuclear transfer (reviewed by Robl \& First, 1985; Prather \& First, 1988a). Therefore this discussion will focus on the latter.

Using mouse embryos McGrath \& Solter (1983) first described the entire nuclear transfer technique, although others had previously developed the cell fusion techniques and speculated about their uses (Graham, 1969). The cells are first treated with cytochalasin, which blocks polymerization of microfilaments, and colchicine, which prevents the polymerization of microtubules, thus together imparting an elasticity to the plasma membrane. This elasticity permits the cells, or parts thereof, to be aspirated into micropipettes without rupturing the plasma membranes. Although these compounds are potentially toxic, in mouse embryos short-term exposure is compatible with normal development to term (Johnson et al., 1981). After exposure of the cells to be manipulated to these compounds the zona pellucida surrounding the embryo is held in position with a holding pipette by gentle aspiration and the zona pellucida is then penetrated with another bevelled pipette. The second pipette is moved into position adjacent to the intracellular (pro)nucleus (or chromosomes). Aspiration of the cellular contents and withdrawal of the pipette, with subsequent pinching of the plasma membranes by the zona pellucida, removes the (pro)nucleus. The membranebounded (pro)nucleus (karyoplast) can then be transferred within the zona pellucida of another egg (Fig. 1). Alternatively, the zona pellucida can be split with a glass needle and a third pipette can be used to transfer the contents from one zona pellucida to another (Willadsen, 1986). Details of glass microtool manufacture for these procedures can be found in Robl (1988). When working with the embryos of some species it may be necessary to centrifuge the egg before visualization of the nucleus. Centrifugation in cattle and pig embryos not only reveals the (pro)nuclei, it is also compatible with continued development (Wall et al., 1985; Wall \& Hawk, 1988).

At this point the karyoplast is adjacent to the recipient cell and the two must be fused together. This is accomplished by cell fusion, which can be induced with an electrical pulse (Berg, 1982), Sendai virus (Graham, 1969) or polyethylene glycol (Fisher \& Goodall, 1981). Both Sendai virus and electrical pulses effectively cause fusion in mouse, rabbit and sheep embryos (Bromhall, 1975; Berg, 1982; McGrath \& Solter, 1983; Robl et al., 1986; Willadsen, 1986; Tsunoda et al., 1987; Stice \& Robl, 1988; Smith \& Wilmut, 1988). Electricity mediated cell fusion has been reported only for cattle embryos, although a few viruses have been tested (Robl et al., 1987). The electrical pulse required for fusion of the karyoplast and recipient cell can also activate the oocyte (Prather $e t a l$., 1987; Stice \& Robl, 1988).

The procedures for nuclear transfer in amphibians are similar (Gurdon \& Laskey, 1970), but not identical to the procedures developed in mammals. Amphibian cells for nuclear transfer are aspirated into a micropipette that has a bore sufficiently small to rupture the plasma membrane, but not completely dissociate the cell. The cellular contents are then deposited in the centre of an oocyte in meiotic metaphase II. Nuclear transfer in mammals incorporates the transfer of a large amount of cytoplasm relative to the size of the recipient oocyte compared with the amphibian and the enclosed cytoplasmic proteins can have undesired affects (Markert \& Urspring, 1963). In some species the physical act of nuclear transfer activates the oocyte, whereas in other species the oocyte must then be activated. In amphibians enucleation is accomplished either manually, by removing the meiotic metaphase II spindle as the egg attemps to emit the second polar body, or with ultraviolet irradiation (reviewed by Gurdon, 1986; Prather \& First, 1989). In mammals the oocyte is either bisected and stained for the presence of the metaphase chromosomes, in which case the 

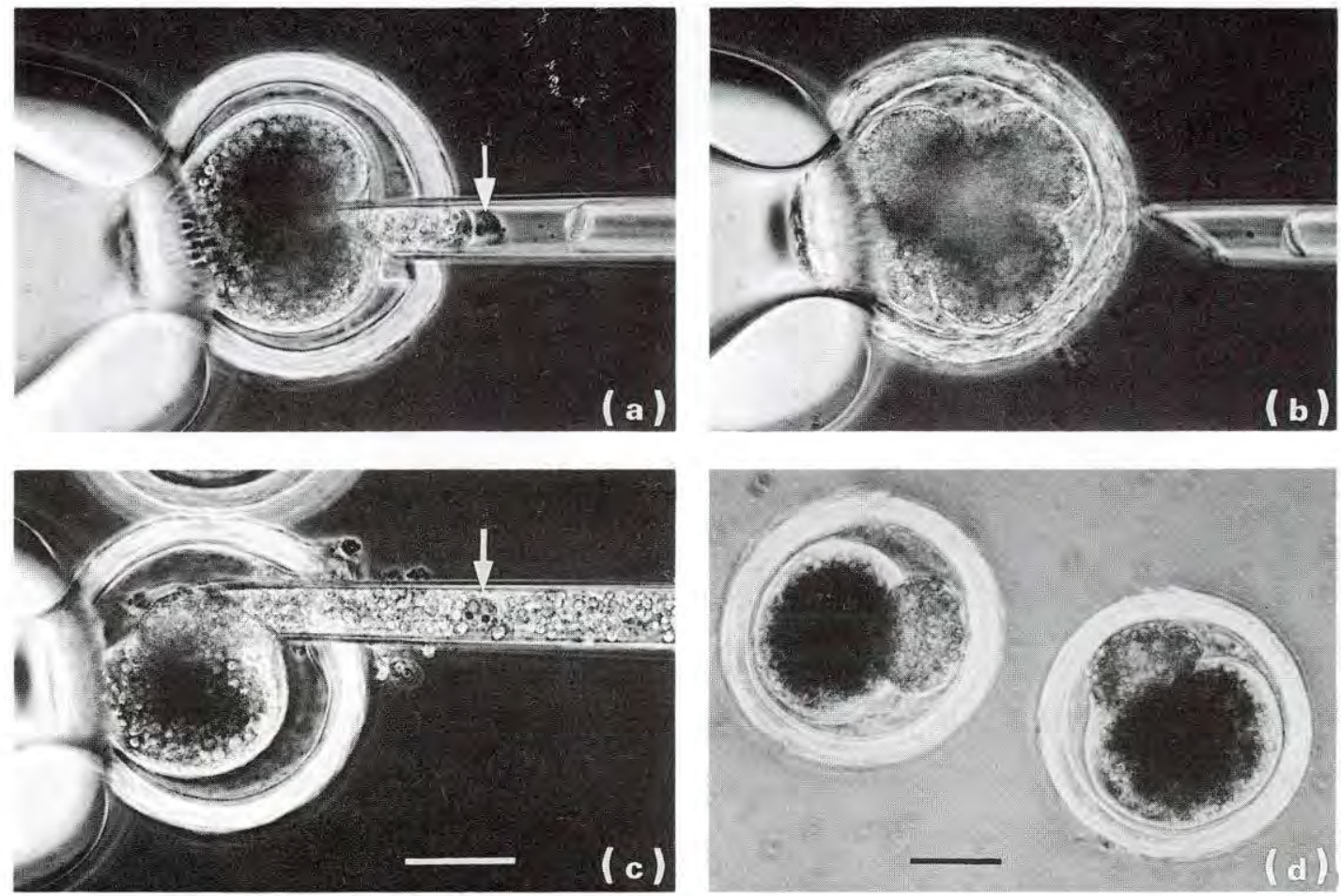

Fig. 1. Nuclear transfer for cloning in pig embryos. (a) Enucleation of a meiotic metaphase II oocyte, arrow denotes first polar body. (b) Four-cell pig embryo before aspiration of the blastomere. (c) Transfer of intact 4-cell stage blastomere to an enucleated oocyte, arrow denotes nucleus. (d) Fusion of a transferred 4-cell stage blastomere to an enucleated oocyte. Note how the membranes between the two cells on the right have formed a smooth surface. Bar $=50 \mu \mathrm{m}$.

chromatin-free half is used as a recipient, or the polar body and underlying cytoplasm are removed (Fig. 1; Fig. 2).

\section{Development}

Development of domestic animal embryos from early cleavage stages can be accomplished in vitro or in vivo. Although in embryos of many species there is a sensitivity to in-vitro culture through early cleavage, a variety of methods have been developed to overcome this block (reviewed by Bavister, 1988). In-vivo development can be in either homologous or heterologous oviducts (reviewed by Boland, 1984), as the environment required for development to the blastocyst stage appears to be relatively nonspecies-specific. For pigs this blocked development in culture has required surgical transfer and development in the oviduct of a recipient pig or sheep. Although some success has recently been achieved with in-vitro culture conditions (B. Day, personal communication; R. S. Prather, D. R. Hagen \& N. L. First, unpublished observations).

\section{Results of cloning}

\section{Efficiency of nuclear transfer}

With experience, technicians performing the micromanipulation can become sufficiently proficient that eventually no oocytes, eggs or cells are accidentally destroyed. How well the 


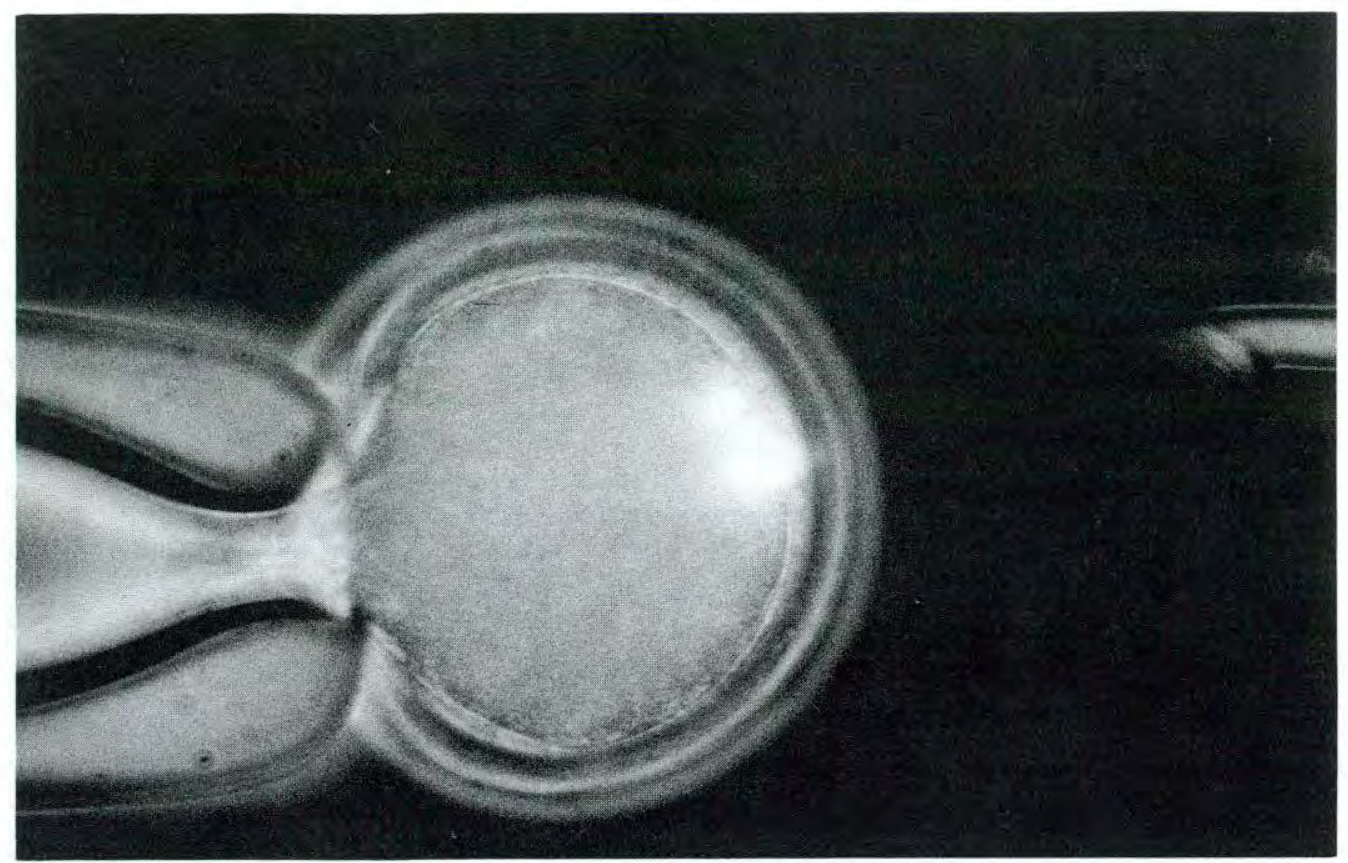

Fig. 2. Meiotic metaphase II cattle oocyte cultured in medium containing Hoechst 33342 stain and illumination with ultraviolet light and a low level of transmitted light. Note the presence of the first polar body and adjacent metaphase chromosomes.

manipulation procedures are carried out is determined by factors such as percentage enucleation of the recipient cell and percentage fusion of the transferred karyoplast to a recipient cell. These vary by species, but in most cases conclusions are confounded because the studies were conducted in different laboratories (Table 1). Oocyte enucleation efficiencies range from $60 \%$ in the cow (Prather et al., 1987) to $92 \%$ in the rabbit (Stice \& Robl, 1988). Electrofusion efficiencies range from $74 \%$ in cattle (Prather et al., 1987), to $90 \%$ in the sheep (Willadsen, 1986) for 8-cell stage nuclei, but decrease in cattle as the two cells become more disproportionate in size (Prather et al., 1987). Electrofusion for pronuclear exchange ranges from $76 \%$ in the pig (Prather et al., 1989) to 80\% in cattle (Robl et al., 1987). Sendai virus fuses sheep nuclear transfer embryos (50\%: Willadsen, 1986), but is relatively ineffective in cattle embryos ( $8 \%$ : Robl et al., 1987). Electrofusion-induced oocyte activation results in $57 \%$ to $81 \%$ formation of one pronucleus in $57 \%$ of cattle (Prather et al., 1987) to $81 \%$ in pig (Prather et al., 1989). The overall expected efficiency of the manipulation procedure is therefore $24 \%$ in cattle, $40 \%$ in rabbits and $52 \%$ in pigs (Table 1 ).

Table 1. Micromanipulation effeciency for nuclear transfer of 8-cell stage nuclei to oocytes (adapted from Robl \& Stice (1989) and Prather \& First (1989))

\begin{tabular}{lcccc}
\hline & $\begin{array}{c}\text { Willadsen } \\
(1986)\end{array}$ & $\begin{array}{c}\text { Prather et al. } \\
(1987)\end{array}$ & $\begin{array}{c}\text { Stice \& Robl } \\
(1988)\end{array}$ & $\begin{array}{c}\text { Prather et al. } \\
(1989)\end{array}$ \\
\hline Species & Sheep & Cattle & Rabbits & Pigs \\
$\quad$ Enucleation & $75 \%$ & $60 \%$ & $92 \%$ & $74 \%$ \\
$\quad$ Activation & - & $57 \%$ & $52 \%$ & $81 \%$ \\
$\quad \begin{array}{l}\text { Electrofusion } \\
\quad \text { (8-cell stage) }\end{array}$ & $90 \%$ & $74 \%$ & $84 \%$ & $87 \%$ \\
Overall & - & $24 \%$ & $40 \%$ & $52 \%$ \\
\hline
\end{tabular}




\section{Development}

Term development has resulted from 4-cell-stage pig nuclei (Prather et al., 1989), 8-cell-stage rabbit nuclei (Stice \& Robl, 1988), 9-16-cell-stage cattle nuclei (Prather et al., 1987) and 16-cellstage nuclei in sheep (Willadsen, 1986).

In amphibians developmental-potential decreases as the embryo proceeds beyond the midblastula stage. For example, Xenopus nuclei from late blastula or early gastrula animal cells, late gastrula endoderm, neurula endoderm and tail bud endoderm stages promote development to feeding tadpoles at progressively decreasing rates of $81 \%, 77 \%, 52 \%$ and $41 \%$, respectively (Gurdon, 1960). The rate of development to adulthood of nuclei from the blastula stage is $\sim 35 \%$ (after removal of data from females which provide oocytes that do not promote development, as there are significant differences between females providing oocytes: Gurdon, 1964).

In domestic animals bisection of embryos has resulted in offspring from sheep (Willadsen, 1979), cattle (Willadsen \& Polge, 1981; Ozil et al., 1982; Williams et al., 1982) and pigs (Willadsen, 1982; Rorie et al., 1985).

\section{Pronuclear exchange}

The rationale for attempting pronuclear exchanges in early embryos is to demonstrate that the techniques used for nuclear transfer are not detrimental to complete development to term and to get a baseline for such development. In the pig $20 \%$ of the pronuclear exchange embryos that fused resulted in term development (Prather et al., 1989), and so the rate of development to term for other types of nuclear transfer were not expected to exceed $20 \%$. In cattle the rate of development to morula/blastocyst on a per-embryo-fused basis is 7\% (5/71: Robl et al., 1987) and assuming a 60\% pregnancy rate from those morulae/blastocyts, an overall rate of development to term is $4 \%$. The success of pronuclear exchanges between zygotes not only shows that nuclear transfer is compatible with development, but also demonstrates a method for evaluating nuclear versus cytoplasmic effects and subsequent interactions on development, as well as studying problems of parental genomic imprinting. When evaluating nuclear versus cytoplasmic affects, although possible with pronuclear exchange, it would require fewer animals if identical nuclei could be placed in all recipient cells. This leads to cloning by nuclear transfer.

\section{Cloning}

Placing identical nuclei in a variety of different cytoplasms should provide a method to evaluate the importance of nuclear versus cytoplasmic inheritance. However, for the nuclei to be identical they must be derived from the same embryo and reprogrammed to direct development from the 1-cell stage through embryo development to term. For example, a 32-cell-stage cow embryo would be expected to form a blastocoele cavity after 1 or 2 cleavages, i.e. at the 64 - to 128 -cell stage. However, if a 32-cell-stage nucleus is transferred to an enucleated, activated oocyte and cavitates after 1 or 2 cleaves, previous information from the mouse (Tarkowski \& Wroblewska, 1967) would suggest that there would be too few cells present to form a competent blastocyst and it would become a trophoblastic vesicle. If, on the other hand, the transferred nucleus was reprogrammed to behave as a zygote nucleus then cavitation would not occur until after 6 or 7 cleavages. This type of nuclear reprogramming is what occurs in amphibians and is gene specific (reviewed by Gurdon, 1986). The change in the timing of blastocoele formation has been characterized in sheep (Willadsen, 1986; Smith \& Wilmut, 1988), cattle (Prather et al., 1987), rabbit (Stice \& Robl, 1988) and pig embryos (Prather et al., 1989), but reprogramming of specific genes has yet to be characterized in mammals. 
The degree to which nuclei must be reprogrammed is thought to vary depending upon their degree of differentiation. Amphibian nuclei that are more advanced in development are less able to redirect complete development from the 1 -cell to an adult than nuclei from less developed embryos. Two hypotheses have been presented to deal with this situation. One states that nuclei from more advanced embryos have gone through more differentiation events and are therefore more difficult to reprogramme. The other states that the difficulty in the reprogramming of more advanced-stage nuclei is simply due to the asynchronies in the length of the cell cycles, i.e. as the amphibian embryo develops beyond the midblastula transition the length of the cell cycle progressively increases, but after nuclear transfer it is required to divide relatively more rapidly. Unfortunately, these two hypotheses are confounded and at the present time cannot be separated (reviewed by Gurdon, 1986; DiBerardino, 1987; Prather, 1989). In domestic mammals the length of the first cell cycle is much longer $(>15 \mathrm{~h}$ ) (Prather \& First, 1988b) than that in amphibians (35 min) (Newport \& Kirschner, 1982). Nuclear transfer in domestic mammals may therefore result in a higher percentage of the embryos developing than in amphibians.

The degree of reprogramming previously shown to occur after nuclear transfer in mammals may be limited, as the transition to zygotic control of development occurs at the 4-cell stage in pig (Norberg, 1970), 4- to 8-cell stage in cattle (Barnes, 1988), 8- to 16-cell stage in sheep (Calarco \& McLaren, 1976; Crosby et al., 1988) and 8-cell stage in rabbit (Van Blerkom \& McGaughey, 1978) embryos. The most convincing reprogramming to date is that of Smith \& Wilmut (1988) using inner cell mass nuclei from sheep blastocysts. The timing of the transition to zygotic control of development in domestic species contrasts with that of the mouse where a major shift in control of development occurs in G2 of the 2-cell stage (Bolton et al., 1984). Nuclear transfer in the mouse would require significant reprogramming immediately after transfer.

Since splitting embryos does not alter the timing of developmental events as does nuclear transfer, fewer embryos can potentially be produced. This is due to the requirement of a threshold number of cells present when the embryo begins cavitation. If too few cells are present a trophoblastic vesicle forms, devoid of an inner cell mass. The number of sections into which an embryo can be split and result in term development is therefore limited to about 4 (reviewed by Robl \& First, 1985).

\section{Potential uses for clones}

The potential uses for clones produced by nuclear transfer are wide. Genomically identical individuals would be extremely valuable for controlled experiments evaluating environmental effects such as nutrition, housing and drugs. Transfer of identical genomes to different sources of cytoplasm would allow evaluation of the interactions between cytoplasm and nuclei. Many nuclear and cytoplasmic effects have been elucidated in the mouse with nuclear transfer (reviewed by Prather \& First, 1989), but none in the pig or other domestic animals. Nuclear transfer also provides a method to study differentiation events in early embryos.

Commercially, the most rapid application of cloning should be to multiply those individuals with a highly desirable genotype such as transgenic animals. For routine commercial application it would be desirable to use this technology in concert with others that would complement it, such as freezing of embryos, sexing of embryos, in-vitro maturation of oocytes from slaughterhouse material and non-surgical embryo transfer. The pig is at a disadvantage compared to cattle and sheep because pig embryos are sensitive to freezing, impossible to collect non-surgically and only recently have they been shown to survive non-surgical embryo transfer (Sims \& First, 1987). The sheep is only slightly better since sheep embryos can tolerate the conditions for frozen storage.

Frozen storage is a prerequisite for identification and marketing of genetically superior individuals, as a clonal line can be stored until their desirability is established. Subsequently, serial nuclear transfer could quickly multiply the clonal line to large numbers and frozen cloned embryos could 
be marketed, although, ideally, the cloning procedure would involve multiplying the donor cells in vitro to large numbers of identical cells before nuclear transfer. The feasibility of this is presently unknown. Marketing may involve guaranteeing a certain level of production, given certain environmental restraints. Superior diets could be formulated that would be specific for each clonal line. The management of a herd of genomically identical animals would probably be easier than nonidentical animals, as they should all respond the same to environmental changes. However, certain precautions should be taken as a herd of identical animals would have identical major histocompatibility complexes and would be susceptible to the same diseases, but again the treatment would be the same for all animals and they should all respond in the same manner.

While great progress has been made in recent years, demonstrating that embryos of cattle, sheep, pigs and rabbits can be cloned, the application of this knowledge will require a much better understanding of the variables affecting the efficiency of each step in the procedure and of the mechanisms controlling cell differentiation, de-differentiation and re-differentiation. This includes understanding the mechanisms and conditions by which the oocyte cytoplasm accomplishes nuclear de-differentiation and allows re-differentiation.

We thank W. R. Grace \& Co. and the USDA for funding to support the authors and their research.

\section{References}

Baker, R.D. \& Shea, B. F. (1985) Commercial splitting of bovine embryos. Theriogenology 23, 2-12.

Bames, F.L. (1988) Characterization of the onset of embryonic control and early embryo development in the bovine embryo. Ph.D. dissertation, University of Wisconsin-Madison.

Bavister, B.D. (1988) Role of oviductal secretions in embryonic growth in vivo and in vitro. Theriogeno$\log y^{29}, 143-154$.

Berg, H. (1982) Fusion of blastomeres and blastocysts of mouse embryos. Bioelectricity and Bioenergetics 9, 223-228.

Boland, M.P. (1984) Use of the rabbit oviduct as a scrcening tool for the viability of mammalian eggs. Theriogenology 21, 126-137.

Bolton, V.N., Oades, P.J. \& Johnson, M.H. (1984) The relationship between cleavage. DNA replication and gene expression in the mouse 2-cell embryo. $J$. Embryol. exp. Morph. 79, 139-169.

Bromhall, J.D. (1975) Nuclear transplantation in the rabbit egg. Nature, Lond. 258, 719-721.

Calarco, P.G. \& McLaren, A. (1976) Ultrastructural observations of preimplantation stages of the sheep. J. Embryol. exp. Morph. 36, 609-622.

Crosby, I.M., Gandolfi, F. \& Moor, R.M. (1988) Control of protein synthesis during early cleavage of sheep embryos. J. Reprod. Fert. 82, 769-775.

DiBerardino, M.A. (1987) Genomic potential of differentiated cells analyzed by nuclear transplantation. $A m$. Zool. 27, 623-644.

Fisher, D. \& Goodall, A.H. (1981) Membrane fusion by viruses and chemical agents. In Techniques in Cellular Physiology, P115, pp. I-36. Elsevier/North Holland.

Graham, C.F. (1969) The fusion of cells with one- and two-cell mouse embryos. In Heterospecific Genome Interaction (Wistar lnst. Symp. Monog. No. 9) pp. 19-35. The Wistar Institute Press.
Gurdon, J.B. (1960) The development capacity of nuclei taken from differentiating endoderm cells of Xenopus laevis. J. Embryol. exp. Morph. 8, 505-526.

Gurdon, J.B. (1964) The transplantation of living cell nuclei. Ads. Morphol. 4, 1-43.

Gurdon, J.B. (1986) Nuclear transplantation in eggs and oocytes. J. Cell Sci., Suppl. 4, 287-3I8.

Gurdon, J.B. \& Laskey, R.A. (1970) Methods of transplanting nuclei from single cultured cells to unfertilized frogs' eggs. J. Embryol. exp. Morph. 24, 227-248.

Johnson, M.H., Pratt, H.P.M. \& Handyside, A.H. (1981) The generation and recognition of positional information in the preimplantation mouse embryo. In Cellular and Molecular Aspects of Implamation, pp. 55-74. Eds S. R. Glasser \& D. W. Bullock. Plenum Press, New York.

Markert, C.L. \& Urspring, H. (1963) Production of reliable persistent changes in zygote chromosomes of Rana pipiens by injected proteins from adult liver nuclei. Devl Biol. 7, 560-577.

McGrath, J. \& Solter, D. (1983) Nuclear transplantation in the mouse embryo by microsurgery and cell fusion. Science, NY 220, 1300-1302.

Newport, J. \& Kirschner, M. (1982) A major transition in early Xenopus embryos. 1. Characterization and timing of cellular changes at the midblastula stage. Cell 30, 675-686.

Nicholas, F.W. \& Smith, C. (1983) Increased rates of genetic change in dairy cattle by embryo transfer and spliting. Aust. J. biol. Sci. 36, 341-353.

Norberg, H.S. (1970) Nucleosphaerides in early pig embryos. Z. Zellforsch. Mikrosk. Anat. 110, 61-71.

Ozil, J.P., Heyman, Y. \& Renard, J.-P. (1982) Production of monozygotic twins by micromanipulation and cervical transfer in the cow. Vet. Rec. 110, 126.

Prather, R.S. (1989) Nuclear transfer in mammals and amphibians: nuclear equivalence, species specificity? In The Molecular Biology of Ferilizarion, pp. 323-340. 
Eds H. Schatten \& G. Schatten, Academic Press, Orlando.

Prather, R.S. \& First, N.L. (1988a) Nuclear transfer in early mammalian embryos. In American Fertility Society Regional Postgraduate Course, Hands-on IVF, Cryopreservation, and Micromanipulation, Madison, Wisconsin, pp. 53-61.

Prather, R.S. \& First, N.L. (1988b) A review of early mouse embryogenesis and its applications to domestic species. J. Anim. Sci. 66, 2626-2635.

Prather, R.S. \& First, N.L. (1989) Nuclear transfer in mammalian embryos. Imt. Rev. Cytol. 120, 169-190.

Prather, R.S., Barnes, F.L., Sims, M.M., Rob], J.M., Eyestone, W.H. \& First, N.L. (1987) Nuclear transplantation in the bovine embryo: assessment of donor nuclei and recipient oocyte. Biol. Reprod. 37, 859-866.

Prather, R.S., Sims, M.M. \& First, N.L. (1989) Nuclear Iransplantation in early porcine embryos. Biol. Reprod. 41, 123-132.

Robl, J.M. (1988) Nuclear transfer in early mammalian embryos. In American Fertility Society Regional Postgraduate Course, Hands-on IVF, Cryopreservation, and Micromanipulation, Madison, Wisconsin, pp. 43-51.

Robl, J.M. \& First, N.L. (1985) Manipulation of gametes and embryos in the pig. J. Reprod. Fert.; Suppl. 33, 101-114.

Robl, J.M. \& Stice, S.L. (1989) Prospects for the commercial cloning of animals by nuclear transplantation. Theriogenology 31, 75-84.

RobI, J.M., Gilligan, B., Critser, E.S. \& First, N.L. (1986) Nuclear transplantation in mouse embryos: assessment of recipient cell stage. Biol. Reprod. 34, 733-739.

Robl, J.M., Prather, R., Barnes, F., Eyestone, W., Northey, D., Gilligan, B. \& First, N.L. (1987) Nuclear transplantation in bovine embryos. J. Anim. Sci. 64, 642-647.

Rorie, R.W., Voelkel, S.A., McFarland, C.W., Southern, L.L. \& Godke, R.A. (1985) Micromanipulation of day-6 porcine embryos to produce split-embryo piglets. Theriogenology 23, 225, abstr.
Sims, M.M. \& First, N.L. (1987) Nonsurgical embryo transfer in swine. J. Anim. Sci.65 (Suppl I), 386, abstr.

Smith, L.C. \& Wilmut, I. (1988) Factors influencing nuclear transplantation in sheep embryos. J. Reprod. Fert. Abstr. Ser. 1, 10, abstr.

Stice, S.L. \& Robl, J.M. (1988) Nuclear reprogramming in nuclear transplant rabbil embryos. Biol. Reprod. $39,657-664$.

Tarkowski, A.K. \& Wroblewska, J. (1967) Development of blastomeres of mouse eggs isolated at the 4- and 8-cell stage. J. Embryol. exp. Morph. 36, 155-180.

Tsunoda, Y., Kato, Y. \& Shioda, Y. (1987) Electrofusion for the pronuclear Iransplantation of mouse eggs. Gamete Res. 17, 15-20.

Van Blerkom, J. \& McGaughey, R.W. (1978) Molecular differentiation of the rabbit ovum. [I. During the preimplantation development of in vivo and in vitro matured oocytes. Dev/ Biol. 63, 15I-164.

Wall, R.J. \& Hawk, H.W. (1988) Development of centrifuged cow zygotes in rabbit oviducts. J. Reprod. Fert. $82,637-680$.

Wall, R.J., Pursel, V.G., Hammer, R.E. \& Brinster, R.L. (1985) Development of porcine ova that were centrifuged to permit visualization of pronuclei and nuclei. Biol. Reprod. 32, 645-651.

Willadsen, S.M. (1979) A method for culture of micromanipulated sheep embryos and its use to produce monozygotic twins. Nasure, Lond. 277, 298-300.

Willadsen, S.M. (1982) Micromanipulation of the large domestic species. In Mammalian Egg Transfer. pp. 185-210. Ed. C. E. Adams. CRC Press, Boca Raton.

Willadsen, S.M. (1986) Nuclear transplantation in sheep embryos. Nature, Lond. 320, 63-65.

Willadsen, S.M. \& Polge, C. (1981) Atlempts to produce monozygotic quadruplets in cattle by blastomere separation. Vet. Rec. 108, 211-213.

Williams, T.J., Elsden, R.P. \& Seidel, G.E., Jr (1982) Identical twin bovine pregnancies derived from bisected embryos. Theriogenology 17, 114, abstr. 